\title{
Households' responses on medical pluralism: Dynamics and determinants of access to traditional medicines in India
}

\author{
Pratap C. Mohanty ${ }^{\mathrm{a}, *}$, Kamal Sharma ${ }^{\mathrm{b}}$ \\ ${ }^{\text {a }}$ Teaches Economics at the Dept. of Humanities and Social Sciences, IIT Roorkee and Specialises on Healthcare Research, India \\ ${ }^{\mathrm{b}}$ Research Assistant for the Sponsored Project on Medical Pluralism and Traditional Medicine in India at the IIT Roorkee, India
}

\section{A R T I C L E I N F O}

\section{Keywords:}

Medical pluralism

Traditional medicines

Dynamics

Determinants

AYUSH

\begin{abstract}
A B S T R A C T
The Indian healthcare practice is pluralistic and unique since it is poised with many challenges. High out of pocket (OOPE) expenditure, scanty institutional facilities, and expensive private healthcare, etc. have strong bearing on adoption of traditional health care practices besides socio-cultural and other gradients. The paper addresses the dynamics and determinants of the access to traditional medicines in India using the representative dataset of the national sample survey (71st and 75th round) conducted in 2014 and 2017-2018. The analysis includes descriptive statistics, conditional Logit regression with marginal effects and Tobit regressions models. Results confirm increased access to traditional medicines even in case of major ailments which has reduced the OOPE on healthcare. The Covid19 pandemic has synergised the use of AYUSH owing to its immunity-boosting measures. The paper also incorporates some of the recent policy initiatives taken over recently in India to facilitate the Ayurveda, Yoga and Naturopathy, Unani, Sowa Rigpa, Siddha and Homoeopathy (AYUSH).
\end{abstract}

\section{Introduction}

Medical Pluralism (MP) is the practice of multiple medical system or the access of both conventional, complementary and alternative medicines (CAM). ${ }^{1}$ This term MP was initially introduced in the mid-1970s when the healthcare access was not limited to only biomedicine based government health facilities. ${ }^{2}$ MP was popularised during 1990s with the inclusion of both traditional medicine (henceforth TM) and modern medicine in the healthcare administration of the western economies. However, the TM in this paper is conceptualised to address the Indian system of medicine such as desi dawai (local medicines), Ayurveda, Yoga and Naturopathy, Unani, Sowa Rigpa, Siddha and Homoeopathy (AYUSH). The modern medicine refers to the practice of Allopathy treatment.

The World Health Organization (WHO) defined TM as "the sum total of the knowledge, skill, and practices based on the theories, beliefs, and experiences of indigenous to different cultures, whether explicable or not, used in the maintenance of health as well as in the prevention, diagnosis, improvement or treatment of physical and mental illness". ${ }^{3}$ The medical pluralism exists in all over the world. Various practitioners in India deliver healthcare services include both licensed and non-licensed ones. The individual healthcare access in India is made through out-of-pocket expenditure (OOPE), free care provided by some medical institutions, health insurance, aids, public spending, etc. ${ }^{4}$ The OOPE on healthcare in India is $64.7 \%$ at present as per the National Health Accounts, 2018.

The treatment seeking behaviour of individuals depends on various factors such as habitat, socio-cultural aspects, religious belief, traditions, ${ }^{5-7}$ socio-economic conditions, customs and practices, nutrition and living conditions, unawareness, education and child-rearing practices, taboos and superstitions ${ }^{8,9}$ etc. The factors like religion, type of family and sector are significantly associated with the visit to health facility centre and nature of treatment. ${ }^{10,11}$ The age of the persons and their gender also play an important role in making healthcare decisions. ${ }^{12}$ Economic support extended by institutions and affordability of the individuals are predominant indicators that influence their health seeking behaviour. ${ }^{7,13,14}$ The high cost and unavailability of modern health care system has serious implication for the livelihood of the poor households. ${ }^{15}$ The role of education in the context of health access is significant. The communities which are poor in educational attainment on average, are more prone to diseases. Studies identified that education level of the individual is positively linked to health awareness and better health access. ${ }^{14,16,17}$

A common believe that people carry regarding the cause of illness is

\footnotetext{
* Corresponding author.

E-mail address: pratap.mohanty@hs.iitr.ac.in (P.C. Mohanty).
} 
owing to the evil touch, evil eye, blind faith, black magic, spirit call, stormy wind and village deity etc. In Sweden, the believes of the Christianity influence the hospital chaplaincy. ${ }^{18}$ Further, the indigenous healers' blessings protect the individuals from the evil eyes and enemies. ${ }^{19}$ These factors indeed dominate the pluralistic patterns of healthcare-seeking behaviour rather than the education attainment and the economic status.

Oyebode et al., examined the use of traditional medicine using the WHO-SAGE database of 2007-10. The empirical result of this study shows that $11.7 \%$ of people in India access traditional medicine; in contrast, less than $3 \%$ reported TM as the primary source of treatment in China, Ghana, Russia and Mexico. In India, lower-income, less educated and rural people were associated with TM. ${ }^{20}$ Another study by Singh et al., took the sample of about 45,000 sick persons from 33,666 households of 35 districts in India. This study shows that about $14 \%$ of ill persons utilise the traditional medicine system. ${ }^{21}$ This study also identifies that the Indian TM is utilised mostly on common ailments and positively linked with income and level of education. The cost of treatment was a little lower for Indian systems of medicines and homeopathy (ISM\&H) as compared to allopathy. ${ }^{21}$ Srinivasan et al., examined the user pattern of traditional medicine in India using national sample survey (NSS) - 68th round data. This study points that the traditional medicine system in India is accessed by nearly $30 \%$ households. ${ }^{22}$ Home based Indian system of medicine is mostly applied for the treatment in India.

A strand of studies highlighted those socio-economic factors are important in accessing different forms of medicines. However, the specific variables and their relationship to the access to TM are mixed. A very few studies address the medical pluralism in a narrower context based in India. No single study has yet examined the socio-economic factors of the access to TM and their dynamics at the national level in India.

The present study estimates results using the raw data of latest two rounds (71st and 75th), the nationally representative cross-sectional household survey conducted by the National Sample Survey Organization (NSSO), Government of India. The analysis is based on the ailment household members (including hospitalization cases). The study examines the pattern of traditional and modern treatment uses for ailment household members over the period of survey. This identifies the covariates based on the Indian households' responses which restrict the use of traditional medicines in India and reviews the policy initiatives of AYUSH.

The remainder of the study is structured as follows. The details of data, variable description and methodology are discussed in Section 2. Section 3 presents the empirical results. The discussion with conclusions and policy initiative for AYUSH are drawn in the final section 4 .

\section{Materials and methods}

\subsection{Data and sample}

This study uses two rounds (71st and 75th) of data from the NSS on household's social consumption on healthcare, conducted by the Ministry of Statistics and Programme Implementation, Government of India. India's Government set up the national sample survey in 1950 to collect socioeconomic data.

The NSS 71st round was conducted between January to June 2014, covers 4577 villages and 3720 urban blocks. This round surveyed 65,932 households and 3,33,104 individuals. The NSS 75th round was surveyed during July 2017-June 2018. 8077 villages and 6187 urban blocks were covered. This survey includes $1,13,823$ households and $5,55,113$ individuals. NSS data collection followed a stratified multistage sampling for both the rounds. ${ }^{23,24}$ The analysis on ailment person is based on the sample size of 37,282 that comprises of 18,825 rural and 18,457 urban respondents in the 71 st round and 43,240 respondents in the 75 th round, consisting of 22,373 rural and 20,867 urban individuals. The analysis is based on the ailment household members including hospitalization cases.

\subsection{Variable description}

The primary objective of the paper is to identify the barriers of access to traditional medicine in India; hence the variables of interest are the modern (allopathy) and traditional (AYUSH \& other) treatment methods adopted by the persons who reported spell of ailment in the last 15 days of the time of survey. Due to the limitations of the data, the paper has considered the treatment variable in binary form, i.e., either traditional medicine or modern medicine. The independent variables of the analysis are included at the individual, household, and community levels. The individual level variables are education, gender, and type of ailment. Whereas the household level variables include household expenditure per capita (proxy of income level), size of the household, source of drinking water and social groups considered as explanatory variables. Community characteristics are the place of residence, region and level of care. These are explained in Table 1.

\subsection{Methodology}

The logit regression model with conditional base category is used to study the factors affecting the nature of treatment since the dependent variable is binary and the follows a logistic distribution. The Tobit regression model is also specified to study the determinants of total healthcare expenditure for a spell of ailment who reported in the last 15 days of the survey. The expenditure at the lower end has been truncated. The entire health expenditure includes total medical spending, transport cost and miscellaneous expenses by the household (food delivery for others, spending on an escort, and care services etc.). The details on these are discussed on the model specification section (2.3.1).

Table 2 presents the nature of treatment received by patients. Individuals use more of modern medicine for the treatment of ailment over the periods. In the NSS 71st round, it is reported that traditional medicine and modern medicine are availed by $6.71 \%$ and $93.29 \%$ persons respectively. The share of the conventional medicine declined by $2.08 \%$ and increased in the use of modern medicine over the period of study. However, there are several factors responsible for the different use of medicines over the period.

The persons belong to ST category use more traditional medicine with comparison to other categories in both the rounds. The ailment persons in the middle age group access comparatively more traditional medicine than others. However, no significant difference is observed among gender and sectors. In household amenities category, we have taken source of drinking water. It is observed that the households which depend on the unprotected source of drinking water have accessed more of traditional treatment methods over the period than the others.

The households belong to the lower quantile are more dependent on traditional treatment. However, several steps have been taken over time and the efficacy are realised by various sections of the society especially during covid pandemics period which includes various forms of Yoga, traditional herbs, vapour and gargling etc. This pattern of access has followed an U-shaped relationship between household usual consumer expenditure and traditional medicine. The households belong to 1st, 2nd and 5th quintile use more of traditional medicine in both rounds than 3rd and 4th quintile households. No clear pattern of use of traditional medicine is observed so far as the level of education is concerned. However, the individuals with graduate, postgraduate and diploma courses use more traditional medicine as compared to others. It is noted that the private institutions use more of traditional treatment than public institutions in both the NSS rounds. Further, our finding from the representative survey data shows that persons with injuries use more of traditional medicine. 
Table 1

Summary statistics of variables.

\begin{tabular}{|c|c|c|c|c|c|c|c|c|c|}
\hline & \multirow[t]{2}{*}{ Measurement } & \multicolumn{4}{|c|}{ NSS 71st Round } & \multicolumn{4}{|c|}{ NSS 75th Round } \\
\hline & & Mean & SD & Min & Max & Mean & SD & Min & Max \\
\hline \multicolumn{10}{|l|}{ Dependent Variables } \\
\hline Nature of treatment & $0=$ traditional treatment, $1=$ allopathy(modern) treatment & 0.94 & 0.23 & 0 & 1 & 0.96 & 0.21 & 0 & 1 \\
\hline Total health expenditure & LCU (rupee) & 870 & 2373.3 & 0 & 196355 & 914.2 & 4125 & 0 & 501000 \\
\hline \multicolumn{10}{|l|}{ Independent Variables } \\
\hline Social group & $1=\mathrm{ST}, 2=\mathrm{SC}, 3=\mathrm{OBC}, 9=$ Other & 4.73 & 3.12 & 1 & 9 & 4.94 & 3.17 & 1 & 9 \\
\hline Residence & $1=$ Rural, $2=$ Urban & 1.49 & 0.5 & 1 & 2 & 1.48 & 0.5 & 1 & 2 \\
\hline Gender & $0=$ Female, $1=$ Male & 0.46 & 0.5 & 0 & 1 & 0.47 & 0.5 & 0 & 1 \\
\hline square age & Member's age square & 2276.7 & 1900.5 & 0 & 11236 & 2502 & 1958.5 & 0 & 12100 \\
\hline Source of drinking water & $0=$ Unprotected source, $1=$ Protected source & 0.86 & 0.35 & 0 & 1 & 0.97 & 0.14 & 0 & 1 \\
\hline $\begin{array}{l}\text { Household UCE (usual } \\
\text { monthly consumer } \\
\text { expenditure) }\end{array}$ & $1=$ lowest, $2=$ lower, $3=$ Middle, $4=$ Higher, $5=$ Highest & 2.89 & 1.37 & 1 & 5 & 2.94 & 1.45 & 1 & 5 \\
\hline Education & $\begin{array}{l}1=\text { Not literate, } 2=\text { literate without any formal schooling, } 3= \\
\text { formal schooling: till primary, } 4=\text { primary to higher secondary, } 5= \\
\text { graduation to post graduate and above }\end{array}$ & 2.66 & 1.41 & 1 & 5 & 2.78 & 1.42 & 1 & 5 \\
\hline Level of care & $1=$ Public institution, $2=$ Private institution & 1.72 & 0.45 & 1 & 2 & 1.66 & 0.47 & 1 & 2 \\
\hline Region & $1=$ performer $2=$ Front runner & 1.83 & 0.38 & 1 & 2 & 1.82 & 0.37 & 1 & 2 \\
\hline Nature of ailment & $1=$ Infection, $2=$ Other, $3=$ Injuries & 1.81 & 0.5 & 1 & 3 & 1.78 & 0.49 & 1 & 3 \\
\hline Household Size & Number of members in household & 5.42 & 2.63 & 1 & 29 & 5.27 & 2.54 & 1 & 31 \\
\hline
\end{tabular}

Source: Authors' estimation.

Note - LCU refers local currency Unit (Indian rupee).

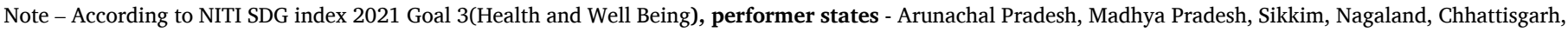
Uttar Pradesh and Assam. Front runner states - Remaining all States and UTs.

\subsubsection{Model specification}

Indian medicinal development and their access have been on the evolutional process over time. There are myths in the access to Indian medicines such as major ailments require modern medicines than the tradition ones. This study focuses on the factors that affect the nature of treatment in the case of an ailment.

The binary choice model is best fitted given the theoretical background. In the binary choice model, one tries to estimate a probability function of an observed discrete random variable - nature of the treatment. It takes two values 1 and 0 where 1 is for the modern treatment and 0 is for traditional treatment.

To ensure the dependent variable lies between 0 and 1 , we transform the dependent variable to cumulative distribution function.

$\left.\operatorname{Prob}\left(Y_{i}=1\right)=f\left(Z_{i}\right)=f\left(\alpha+\beta X_{i}\right)\right)$, Where CDF (.) is selected in advance and assume $E\left(\mu_{i}\right)=0$.

In logit model, we choose logistic (cumulative distribution) function:

$\operatorname{Prob}\left(Y_{i}=1\right)=P_{i}=\frac{1}{1+e^{-\left(\alpha+\beta X_{i}\right)}}=\frac{1}{1+e^{-Z_{i}}}=\frac{e^{Z_{i}}}{1+e^{Z_{i}}}$

$1-P_{i}=\frac{1}{1+e^{Z_{i}}} ; \frac{P_{i}}{1-P_{i}}=\frac{1+e^{Z_{i}}}{1+e^{-Z_{i}}}=e^{Z_{i}}$

$\operatorname{Logit}_{i}=\ln \left(\frac{P_{i}}{1-P_{i}}\right)=Z_{i}=\alpha+\beta X_{i}$

$\operatorname{Prob}\left(Y_{i}=1\right)$ tends to 0 as $\alpha+\beta X_{i}$ tends to minus infinity and $\operatorname{Prob}\left(Y_{i}=1\right)$ tends to 1 as $\alpha+\beta X_{i}$ tends to infinity. Thus, probabilities from the logit model will be between 0 and 1 .

The theoretical construct as discussed suggests that the explanatory variables are relevant for the model. These are demographic variables, household amenities, economic factor, education, nature of ailment etc. Hence, we construct the following logit model considering the relevant variables.

\subsubsection{Tobit model}

The total health expenditure in the situation of ailment varies for each household member. The difference can arise because of the nature of the disease, nature of the treatment, education, household income etc. We are interested to see whether these factors result in significant reduction in expenditure of the households.

We have divided the total expenditure in deciles and censored the data from above and below. Therefore, a simple OLS estimation procedure may give biased estimates. In such cases, the Tobit regression model gives unbiased result because this model handles the skewed and truncated data.

$y_{i}^{t}=\beta^{n} x_{i}+\varepsilon_{i}$

$y_{i}=y_{i}^{t}$ if $y_{i}^{t}>c$, and

$y_{i}=0$, otherwise

Where $x_{i}=$ explanatory variable, $y_{i}=$ dependent variable, $\beta^{n}=$ coefficient of $x_{i}, y_{i}^{t}=$ latent variable, $\mathrm{c}=$ constant and $\varepsilon_{i}\left(N\left(0, \sigma^{2}\right)\right)=$ error term. To solve $\beta$ and $\sigma$ we need to maximize likelihood function for all observation ofy $y_{i}$ and $x_{i}$.

$L=\prod_{y_{i}=0} 1-F_{i} \prod_{y_{i}>0} \frac{1}{\left(2 \pi \sigma^{2}\right)^{1 / 2}} e^{-\left(1 / 2 \sigma^{2}\right)\left(y_{i}-\beta^{n} x_{i}\right)^{2}}$

Where $F_{i}=\int_{-\infty}^{\beta^{n} x_{i j}} \frac{1}{(2 \pi)^{1 / 2}} e^{-\left(t^{2 / 2}\right) d t}$.

In the NSS 71st round data for ailment, the upper and lower limit of total health expenditure per person are defined as Rs.1802 and Rs.50

Treatment $_{i}=\beta_{0}+\beta_{1}$ social_group $_{i}+\beta_{2}$ residence $_{i}+\beta_{3}$ gender $_{i}+\beta_{4}$ square_age $_{i}+\beta_{5}$ source_drink_water $_{i}$

$+\beta_{6} H H S_{-} U C E_{i}+\beta_{7}$ edu $i+\beta_{8}$ level_care $_{i}+\beta_{9}$ region $+\beta_{10}$ ailment_nature $_{i}+\beta_{11} H H S_{-}$size $_{i}+\varepsilon$ 
Table 2

Nature of treatment received by patients (in \%) [weighted].

\begin{tabular}{|c|c|c|c|c|c|c|c|}
\hline & & \multicolumn{3}{|c|}{ 71st Round } & \multicolumn{3}{|c|}{ 75th round } \\
\hline & & $\begin{array}{l}\text { Sample } \\
\text { Size }\end{array}$ & $\begin{array}{l}\text { Traditional } \\
\text { treatment }\end{array}$ & $\begin{array}{l}\text { Modern } \\
\text { treatment }\end{array}$ & $\begin{array}{l}\text { Sample } \\
\text { Size }\end{array}$ & $\begin{array}{l}\text { Traditional } \\
\text { treatment }\end{array}$ & $\begin{array}{l}\text { Modern } \\
\text { treatment }\end{array}$ \\
\hline \multicolumn{8}{|l|}{ Demographic characteristics } \\
\hline \multirow[t]{4}{*}{ Social group } & ST & 2765 & 8.03 & 91.97 & 2894 & 6.63 & 93.37 \\
\hline & SC & 6133 & 5.61 & 94.39 & 6864 & 3.96 & 96.04 \\
\hline & OBC & 15657 & 6.37 & 93.63 & 17400 & 4.43 & 95.57 \\
\hline & Other & 12689 & 7.54 & 92.46 & 16061 & 4.89 & 95.11 \\
\hline \multirow[t]{2}{*}{ Residence } & Rural & 18825 & 6.65 & 93.35 & 22362 & 4.64 & 95.36 \\
\hline & Urban & 18457 & 6.81 & 93.19 & 20857 & 4.6 & 95.4 \\
\hline \multirow[t]{2}{*}{ Gender } & Male & 17146 & 6.07 & 93.93 & 20399 & 4.13 & 95.87 \\
\hline & Female & 20098 & 7.23 & 92.77 & 22840 & 5.05 & 94.95 \\
\hline \multirow[t]{6}{*}{ Age } & Age group(0-14) & 7240 & 5.27 & 94.73 & 8013 & 2.95 & 97.05 \\
\hline & Age group(15-29) & 4612 & 7.14 & 92.86 & 4440 & 3.99 & 96.01 \\
\hline & Age group(30-44) & 5960 & 6.63 & 93.37 & 5611 & 6.01 & 93.99 \\
\hline & Age group(45-59) & 9194 & 7.81 & 92.19 & 11473 & 4.78 & 95.22 \\
\hline & Age group $(60-74)$ & 8086 & 6.62 & 93.38 & 10650 & 5.7 & 94.3 \\
\hline & Age group(75-115) & 2152 & 6.77 & 93.23 & 3024 & 3.32 & 96.68 \\
\hline \multicolumn{8}{|l|}{ Household amenities } \\
\hline \multirow[t]{2}{*}{ Source of drinking water } & Unprotected source & 5200 & 9.3 & 90.7 & 900 & 6.53 & 93.47 \\
\hline & Protected source & 32044 & 6.34 & 93.66 & 42319 & 4.6 & 95.4 \\
\hline \multicolumn{8}{|l|}{ Economic Factor } \\
\hline \multirow{5}{*}{$\begin{array}{l}\text { Household usual consumer } \\
\text { expenditure }\end{array}$} & Lowest & 8192 & 7.51 & 92.49 & 9570 & 5.19 & 94.81 \\
\hline & Lower & 6732 & 6.24 & 93.76 & 9528 & 3.99 & 96.01 \\
\hline & Middle & 9154 & 6.3 & 93.7 & 6846 & 3.86 & 96.14 \\
\hline & Higher & 7290 & 6.4 & 93.6 & 8632 & 4.67 & 95.33 \\
\hline & Highest & 5875 & 6.67 & 93.33 & 8643 & 5.21 & 94.79 \\
\hline \multicolumn{8}{|l|}{ Education } \\
\hline & Not literate & 14147 & 5.97 & 94.03 & 14935 & 4.28 & 95.72 \\
\hline & $\begin{array}{l}\text { Literate without any formal } \\
\text { schooling }\end{array}$ & 449 & 8.52 & 91.48 & 540 & 5.8 & 94.2 \\
\hline & Formal schooling: till primary & 9440 & 2.86 & 97.14 & 10808 & 3.39 & 96.61 \\
\hline & Primary to Higher Secondary & 10250 & 6.72 & 93.28 & 12763 & 4.17 & 95.83 \\
\hline & $\begin{array}{l}\text { Graduation to post graduation } \\
\text { and above }\end{array}$ & 2957 & 6.36 & 93.64 & 4173 & 5.23 & 94.77 \\
\hline \multirow[t]{2}{*}{ Region } & Performer & 6418 & 7.64 & 92.36 & 7369 & 4.2 & 95.8 \\
\hline & Front runner & 30864 & 6.52 & 93.48 & 35850 & 4.74 & 95.26 \\
\hline \multirow[t]{2}{*}{ Level of care } & Public institution & 9121 & 5.05 & 94.95 & 12989 & 2.38 & 97.62 \\
\hline & Private institution & 23648 & 5.75 & 94.25 & 25052 & 4.29 & 95.71 \\
\hline \multirow[t]{3}{*}{ Nature of ailment } & Infection & 8563 & 4.11 & 95.89 & 11002 & 2.01 & 97.99 \\
\hline & Other & 26882 & 7.42 & 92.58 & 30794 & 5.81 & 94.19 \\
\hline & Injuries & 1837 & 12.01 & 87.99 & 1444 & 7.42 & 92.58 \\
\hline Total & & 42539 & 6.71 & 93.29 & 36200 & 4.63 & 95.37 \\
\hline
\end{tabular}

Source: Authors' estimation.

Note: Patients: persons reporting illness during reference period of last 15 days).

respectively, and in the 75th round these are of Rs.1910 and Rs.57.

We estimate the left and right censored Tobit regression model as given below the rural areas.

The average marginal effect of the regression coefficient is presented in the appendix table A1.

health $\exp _{i}=\beta_{0}+\beta_{1}$ social_group $_{i}+\beta_{2}$ residence $_{i}+\beta_{3}$ gender $_{i}+\beta_{4}$ square_age $_{i}$

$+\beta_{5} H H S_{-} U C E_{i}+\beta_{6}$ edu $_{i}+\beta_{7}$ level_care $_{i}+\beta_{8}$ ailment_nature $_{i}+\beta_{9}$ treatment $_{i}+\beta_{10}$ region $+\varepsilon$

\section{Empirical results}

We observe from Tables 3 and 4 that in the NSS 71st and 75th round, General and OBC category use more of modern treatment than SC and ST category. The total health expenditure of Other and OBC category is higher than the ST and SC category. Sector dummy significantly impact the process of treatment as the adjusted regression coefficient in both rounds comes out significant and shows that the rural sector uses more of traditional medicine with comparison to urban areas. In the metropolitan area, the total health expenditure in ailment case is lower than
The adjusted regression coefficient of gender dummy for NSS 71st and 75th round is positive and significant which suggests that males use more of modern treatment. The total health expenditure is higher for male in comparison to female. Regarding the health facilities in the household, the existing studies consider this as part of the household amenities. We have taken the source of drinking water as a proxy. The people who use protected water sources use more modern treatment in ailment than those who use unprotected drinking water sources. Households which have protected source of drinking water use $51.8 \%$ and $27.5 \%$ more modern medicines in the 71 st round and 75 th round respectively.

We have taken the square of age to check the impact of the nonlinearity in the age on the access to medicines. The adjusted 
Table 3

Logit model estimates for correlates of forms of treatment.

\begin{tabular}{|c|c|c|c|c|c|}
\hline \multicolumn{2}{|c|}{ (Dependent Variables: Use of treatment) } & \multicolumn{2}{|l|}{ 71st Round } & \multicolumn{2}{|l|}{ 75th round } \\
\hline Correlates/Variables & & unadjusted reg. coff.(SE) & adjusted reg. coff.(SE) & unadjusted reg. coff.(SE) & adjusted reg. coff.(SE) \\
\hline \multicolumn{6}{|l|}{ Demographic characteristics } \\
\hline \multirow[t]{4}{*}{ Social group } & ST @ & & & & \\
\hline & SC & $0.35^{* * *}[0.09]$ & $-0.15[0.13]$ & $0.47^{* * *}[0.09]$ & $0.18[0.13]$ \\
\hline & OBC & $0.42^{* * *}[0.08]$ & $-0.11[0.12]$ & $0.34 * * *[0.08]$ & $0.14[0.12]$ \\
\hline & Other & $0.41 * * *[0.08]$ & $-0.07[0.12]$ & $0.43^{* * *}[0.08]$ & $0.21[0.12]$ \\
\hline \multirow[t]{2}{*}{ Residence } & Rural @ & & & & \\
\hline & Urban & $0.07[0.04]$ & $0.12 *[0.06]$ & $0.19 * * *[0.05]$ & $0.13 *[0.06]$ \\
\hline \multirow[t]{2}{*}{ Gender } & Female@ & & & & \\
\hline & Male & $0.13 * * *[0.05]$ & $0.14 * *[0.05]$ & $0.14 * * *[0.05]$ & $0.23^{* * *}[0.06]$ \\
\hline Square age & Square age & $0[0]$ & $0.0^{* * *}[0]$ & $0[0]$ & $0 * * *[0]$ \\
\hline \multicolumn{6}{|l|}{ Household amenities } \\
\hline \multirow[t]{2}{*}{ Source of drinking water } & Protected source@ & & & & \\
\hline & Unprotected source & $-0.52^{* * *}[0.06]$ & $-0.55^{* * *[0.07]}$ & $-0.43^{* * *}[0.14]$ & $-0.27[0.17]$ \\
\hline \multicolumn{6}{|l|}{ Economic Factor } \\
\hline \multirow[t]{5}{*}{ Household UCE } & Lowest@ & & & & \\
\hline & Lower & $0.16^{* *[0.07]}$ & $0.09[0.08]$ & $0.18^{* * *[0.07]}$ & $0.15[0.08]$ \\
\hline & Middle & $0.23 * * *[0.07]$ & $0.16 *[0.08]$ & $0.41 * * *[0.08]$ & $0.34 * * *[0.1]$ \\
\hline & Higher & $0.2^{* * *}[0.07]$ & $0.2 *[0.09]$ & $0.11 * *[0.07]$ & $0.06[0.1]$ \\
\hline & Highest & $0.29 * * *[0.07]$ & $0.3^{* *}[0.10]$ & $0.35 * * *[0.07]$ & $0.28 *[0.1]$ \\
\hline \multirow[t]{5}{*}{ Education } & Not literate@ & & & & \\
\hline & Literate without any formal schooling & $-0.35[0.18]$ & $-0.12[0.25]$ & $-0.12[0.21]$ & $0.01[0.28]$ \\
\hline & Formal schooling: till primary & $-0.11[0.06]$ & $-0.14 *[0.07]$ & $-0.15^{*}[0.06]$ & $-0.25^{* * *[0.07]}$ \\
\hline & Primary to higher secondary & $-0.09[0.06]$ & $-0.13[0.07]$ & $-0.23^{* * *}[0.06]$ & $-0.34 * * *[0.07]$ \\
\hline & Graduation to post graduate and above & $-0.14[0.09]$ & $-0.3^{* *}[0.1]$ & $-0.05[0.09]$ & $-0.25 *[0.11]$ \\
\hline \multirow[t]{2}{*}{ Region } & Performer@ & & & & \\
\hline & Front runner & $0.12 *[0.06]$ & $-0.01[0.08]$ & $0.15^{* * *}[0.06]$ & $-0.01[0.08]$ \\
\hline \multirow[t]{2}{*}{ Level of care } & Public institution@ & & & & \\
\hline & Private institution & $-0.18^{* * *}[0.06]$ & $-0.22^{* * *[0.06]}$ & $-0.47^{* * *}[0.07]$ & $-0.51^{* * *[0.06]}$ \\
\hline \multirow[t]{3}{*}{ Nature of ailment } & Infection @ & & & & \\
\hline & Other & $-0.40 * * *[0.06]$ & $-0.49 * * *[0.08]$ & $-0.41^{* * *}[0.06]$ & $-0.57^{* * *[0.08]}$ \\
\hline & Injuries & $-0.52^{* * *[0.11]}$ & $-0.58^{* * *[0.12]}$ & $-0.53^{* * *}[0.13]$ & $-0.58^{* * *[0.15]}$ \\
\hline Household Size & Size & $0.03^{* * *}[0.01]$ & $0.02[0.01]$ & $0.02[0.01]$ & $0.01[0.13]$ \\
\hline Constant & & & $3.5^{* * *}[0.16]$ & & $3.58^{* * *[0.17]}$ \\
\hline Observations & & 32732 & 38019 & & \\
\hline LR Chi2(25) & & 162.04 & 201.98 & & \\
\hline Log Likelihood & & -6192.31 & -5931.03 & & \\
\hline Pseudo R2 & & 0.013 & 0.017 & & \\
\hline
\end{tabular}

Note: variable@ is reference group, adj. coefficient: Adjusted with all cofactors.

Significance level: *p $<.1 ;{ }^{* *} \mathrm{p}<.05 ;{ }^{* * *} \mathrm{p}<.01$, Standard Error is in the parenthesis.

Source: Authors' estimation.

regression coefficient of the latest round confirms the relationship as positive and significant. However, the total health expenditure is also positively and significantly related to age. The household's usual consumer expenditure (UCE) is considered as the proxy of standard of living. The higher is the UCE, the households tend to use more of modern medicine than others.

Education as a variable is significantly related to medicinal practices except for some categories. This is also observed in case of the total health expenditure. The higher educated persons use more of traditional treatment and health expenditure is higher for higher educated person.

The government of India has attempted to publicise the users' benefits of traditional benefits. However, it is to be noted that the public institutions had applied much of the modern medicines than the traditional practices. The public institutions have indeed increased the use of modern medicines in case of ailments. Our regression coefficients come out to be significant. The total health expenditure in private institutions is higher than public institutions.

The use of the modern and traditional treatment also changes with the nature of ailment. In case of injuries, people use less of modern treatment than infection and other diseases. The total health expenditure is significant and higher for injuries than other ailments. The health expenditure due to modern medicine is higher than the traditional medicine.

We identified health infrastructure by states to explain their regional variation. The information regarding this, is based on NITI's SDG Index 2021 (Goal 3: health and wellbeing) of Govt. of India. This index has categorised health infrastructure of states into performer and front runner (details mentioned in Table 1) group. The unadjusted regression coefficient for both round is significant. The performer state and UTs use more of traditional treatment in comparison to the front runner states. The adjusted regression coefficients are insignificant.

We also examined a two-sample $t$-test (Table 5). We find that the mean medicine expenditure with AYUSH is Rs 194.04 as compared to Rs 573.75 of medicine expenditure other than AYUSH. The mean difference is also significant in both the rounds. However, the difference is higher in the latest round.

\section{Discussion and conclusion}

The medical pluralism is pervasive in the society, and various nature of needs are not a choice but a compulsion because of socio-economic and demographic conditions. The large section of the society uses more of modern treatment and believes the effectiveness of modern treatment. Financial situation, household amenities, nature of ailments and demographic conditions etc. affect the nature of the treatment.

The present study finds that the use of modern medicine is higher in both rural and urban areas. A significant difference is noted between the rural and urban areas so far as the access to traditional medicine is concerned. The practice of medicine is owing to the spell of ailment, the quality of care and availability of services. Interestingly, we observe that private institutions use more of traditional medicine than public institutions. Private institutions are widespread and catering to the local 
Table 4

Tobit model estimates for correlates of total health expenditure.

\begin{tabular}{|c|c|c|c|}
\hline \multicolumn{2}{|c|}{$\begin{array}{l}\text { (Dependent Variable: Total health } \\
\text { expenditure) }\end{array}$} & \multirow{2}{*}{$\begin{array}{l}\text { 71st round } \\
\text { adjusted reg. } \\
\text { coff.(SE) }\end{array}$} & \multirow{2}{*}{$\begin{array}{l}75 \text { th round } \\
\text { adjusted reg. } \\
\text { coff.(SE) }\end{array}$} \\
\hline Correlates/Var & & & \\
\hline \multirow[t]{5}{*}{ Social group } & ST@ & & \\
\hline & $\mathrm{SC}$ & $-66.2^{* * *}$ & $-83.65^{* * *}$ \\
\hline & & [18.32] & {$[18.1]$} \\
\hline & OBC & $\begin{array}{l}-66.78^{* * *} \\
{[16.88]}\end{array}$ & $\begin{array}{l}-89.57 * * * \\
{[16.67]}\end{array}$ \\
\hline & Other & $-19.14[17.37]$ & $\begin{array}{l}-73.72^{* * *} \\
{[17.01]}\end{array}$ \\
\hline \multirow[t]{2}{*}{ Residence } & Rural @ & & \\
\hline & Urban & $\begin{array}{l}-31.42^{* * *} \\
{[8.14]}\end{array}$ & $\begin{array}{l}-27.23^{* * *} \\
{[8.08]}\end{array}$ \\
\hline \multirow[t]{2}{*}{ Gender } & Female @ & & \\
\hline & Male & $31.78 * * *[7.78]$ & $45.08^{* * *[7.45]}$ \\
\hline Square Age & Square age & $0.02 * * *[0.002]$ & $0.01[0.002]$ \\
\hline \multirow[t]{6}{*}{ Education } & Not literate@ & & \\
\hline & $\begin{array}{l}\text { Literate without any } \\
\text { formal schooling }\end{array}$ & $5.56[35.19]$ & $51.71[33.71]$ \\
\hline & $\begin{array}{l}\text { Formal schooling: till } \\
\text { primary }\end{array}$ & $7.73[9.97]$ & $-6.14[9.77]$ \\
\hline & $\begin{array}{l}\text { Primary to higher } \\
\text { secondary }\end{array}$ & $\begin{array}{l}85.31^{* * *} \\
{[10.01]}\end{array}$ & $77.36^{* * *[9.58]}$ \\
\hline & Graduation to post & $153.35^{* * *}$ & $155.53^{* * *}$ \\
\hline & graduate and above & {$[15.81]$} & [14.1] \\
\hline \multirow[t]{2}{*}{ Region } & Performer@ & & \\
\hline & Front-runner & $\begin{array}{l}-179.45^{* * *} \\
{[10.27]}\end{array}$ & $\begin{array}{l}-198.79 * * * \\
{[10.13]}\end{array}$ \\
\hline \multirow[t]{2}{*}{ Level of care } & Private institution & $\begin{array}{l}270.41^{* * * *} \\
{[9.05]}\end{array}$ & $\begin{array}{l}362.04 * * * \\
{[8.08]}\end{array}$ \\
\hline & Public institution@ & & \\
\hline \multirow{3}{*}{$\begin{array}{r}\text { Nature of } \\
\text { ailment }\end{array}$} & Infection @ & & \\
\hline & Other & $\begin{array}{l}81.55^{* * *} \\
{[10.19]}\end{array}$ & $52.14 * * *[9.8]$ \\
\hline & Injuries & $\begin{array}{l}320.69 * * * \\
{[19.63]}\end{array}$ & $\begin{array}{l}429.78^{* * *} \\
{[22.01]}\end{array}$ \\
\hline Household & Lowest@ & & \\
\hline \multirow[t]{5}{*}{ UCE } & Lower & $17.67[12.46]$ & $26.21 *[11.35]$ \\
\hline & Middle & $31.9 * *[11.64]$ & $-5.57[12.41]$ \\
\hline & Higher & $\begin{array}{l}70.35^{* * *} \\
{[12.46]}\end{array}$ & $19.55[11.88]$ \\
\hline & Highest & $162.45^{* * *}$ & $60.15^{* * *}$ \\
\hline & & {$[13.71]$} & [12.57] \\
\hline \multirow{3}{*}{$\begin{array}{l}\text { Nature of } \\
\text { treatment }\end{array}$} & Traditional @ & & \\
\hline & Modern & $228.09^{* * *}$ & $133.44 * * *$ \\
\hline & & [17.97] & {$[19.48]$} \\
\hline \multirow[t]{2}{*}{ Constant } & & $209.94 * * *$ & $389.19^{* * *}$ \\
\hline & & {$[26.85]$} & {$[27.25]$} \\
\hline \multicolumn{2}{|l|}{ Number of obs } & 31001 & 36596 \\
\hline \multicolumn{2}{|l|}{ Pseudo R2 } & 0.006 & 0.0069 \\
\hline \multicolumn{2}{|l|}{ LR chi(24) } & 2484.86 & 3396.98 \\
\hline
\end{tabular}

Note: variable@ is reference group, adj. coefficient: Adjusted with all cofactors. Significance level: ${ }^{*} \mathrm{p}<.1 ;{ }^{*} \mathrm{p}<.05 ;{ }^{* * *} \mathrm{p}<.01$. Standard Error is in the parenthesis.

Source: Authors' estimation.

people whereas the public institutions are limited and located away. Clinical tested medicines are provided in the public hospitals. Therefore, it is expected to have higher use of modern medicine in the public institutions. Moreover, the better educated persons understand the efficacy of traditional medicines. It is also perceived that traditional medicine has no side effects. Hence, educated people prefer to practice the use of traditional medicine for their healthcare.

Among the determinants of treatment utilization in India, ST persons, less household size, ailing for lesser days, using unprotected drinking water, type of ailment, injury, and households with less income have higher probability of taking traditional medicine whereas the people who are OBC, ailing for longer days, infection led ailment, better household amenities, have a higher probability of taking modern medicine for ailment treatment. ${ }^{15}$ The total health expenditure is higher for
Table 5

Two sample $t$-test with equal variance for expenditure on AYUSH.

\begin{tabular}{|c|c|c|c|c|c|c|}
\hline \multirow[t]{2}{*}{ Variable } & \multicolumn{3}{|c|}{ 71st Round } & \multicolumn{3}{|c|}{ 75th Round } \\
\hline & Mean & SE & SD & Mean & SE & SD \\
\hline $\begin{array}{l}\text { medicine } \\
\text { expenditure } \\
\text { AYUSH }\end{array}$ & 194.04 & 8.8 & 637.8 & 119.9 & 4.86 & 529.7 \\
\hline $\begin{array}{l}\text { medicine } \\
\text { expenditure } \\
\text { other than } \\
\text { AYUSH }\end{array}$ & 573.75 & 6.7 & 1155.96 & 592.2 & 16.16 & 3060.1 \\
\hline Combined & 517.5 & 5.87 & 1103.1 & 474.5 & 12.23 & 2672.7 \\
\hline Difference & $-379.7^{* * *}$ & 16.4 & & $-472.3^{* * *}$ & 28.2 & \\
\hline
\end{tabular}

Note: significance level **p $<.05$.

Source: Authors' estimation.

modern treatment with comparison to traditional treatment. The entire health expenditure is lesser for STs, among younger age, those use unprotected drinking water sources, and take medical facilities from public institutions. ${ }^{8,9}$

The responses of the households surveyed through the NSS confirms to the fact that the practice of traditional medicine has been declined over the period. This is owing to the lack of knowledge about the need of the AYUSH. Nonetheless, certain sections of the society still continues to access AYUSH due to their strong faith in it. ${ }^{22}$

In the recent years the Govt. of India has taken several initiatives, however, the adaptability of this is time consuming. The Ministry of AYUSH has been instrumental in promoting the use of TM. The socioeconomic and cultural factors are also equally important along education attainment of the members of the households. Behavioural aspects of the practices by different households need to be examined. The National Health Policy (NHP) of 2017 has highlighted the recommendation to mainstream the AYUSH, considering the potential of it in the pluralistic integrative system of healthcare and incorporating in the National Health Mission. ${ }^{25,26}$ Some other steps have also been taken to promote the TM in India including National Ayush Mission, Pradhan Mantri Jan Arogya Yojana, education policy for AYUSH, growth of medical plants, and research in the AYUSH system.

The present study identifies predictors of accessing different forms of medicine in India. The study also highlights the dynamics of access to medicines as well. These aspects help in making appropriate policies which would cater to the need of the larger segment of Indian society. The existing policies on promoting traditional medicine have been reviewed for the better interest of our population and to highlight the scope for integrating different forms of treatment in India.

\subsection{Limitations}

This paper is limited to the explanation for the ailment of persons reported during last 15 days of the survey. The distance to health facility and their availability are reported to have better bearing with health seeking behaviour. But, these variables are not considered in the analysis since this is not covered in the survey. However, we have used NITI's SDG index on health and well-being as the proxy of health facilities in different states. Community awareness program is identified as an important predictor in the literature. Besides, information on monitoring and evaluation with training to the health professionals is also limited. The information regarding standardization and models of integration are also limited in the paper. The survey also doesn't cover the cultural factors that influence the access to medicine.

\section{Authors' statement}

The authors of the paper contributed as per the following:

Dr. Pratap C. Mohanty - Conceptualization; Formal analysis; Funding acquisition; Investigation; Methodology; Project administration; 
Resources; Software; Supervision; Validation; Roles/Writing - original draft; Writing - review \& editing, Kamal Sharma - Data curation; Formal analysis; Methodology; Resources; Software; Visualization.

\section{Acknowledgement}

The authors acknowledge the Ministry of Statistics and Program Implementation, Govt. of India for the unit level data support. We also thank the research division of ICSSR for funding this study.

\section{Appendix}

Table A1

Marginal effects for logit model (Delta method)

\begin{tabular}{|c|c|c|c|}
\hline & & 71st round & 75th round \\
\hline Dependent variable & \multicolumn{3}{|c|}{ use of modern treatment(traditional)in last 15 days } \\
\hline variables/correlates & & $\mathrm{dy} / \mathrm{dx}[\mathrm{SE}]$ & $\mathrm{dy} / \mathrm{dx}[\mathrm{SE}]$ \\
\hline \multicolumn{4}{|c|}{ Demographic characteristics } \\
\hline \multirow[t]{4}{*}{ Social group } & ST @ & & \\
\hline & SC & $-0.006[0.006]$ & $0.007[0.005]$ \\
\hline & OBC & $-0.005[0.005]$ & $0.005[0.004]$ \\
\hline & Other & $-0.004[0.005]$ & $0.007[0.004]$ \\
\hline \multirow[t]{2}{*}{ Residence } & Rural@ @ & & \\
\hline & Urban & $-0.005 * *[0.002]$ & $0.005^{* *}[0.002]$ \\
\hline \multirow{2}{*}{ Gender } & female@ & & \\
\hline & Male & $0.006^{* * *}[0.002]$ & $0.008^{* * *[0.002]}$ \\
\hline \multirow{2}{*}{\multicolumn{4}{|c|}{ Household amenities }} \\
\hline & & & \\
\hline \multirow[t]{2}{*}{ Source of drinking water } & Protected source@ & & \\
\hline & Unprotected source & $-0.024 * * *[0.003]$ & $-0.009[0.006]$ \\
\hline \multicolumn{4}{|l|}{ Economic Factor } \\
\hline \multirow[t]{5}{*}{ Household UCE } & Lowest@ & & \\
\hline & Lower & $0.004[0.004]$ & $0.005 *[0.003]$ \\
\hline & Middle & $0.007 * *[0.004]$ & $0.012 * * *[0.003]$ \\
\hline & Higher & $0.009 * *[0.004]$ & $0.002[0.003]$ \\
\hline & Highest & $0.013^{* * *}[0.005]$ & $0.1 * *[0.004]$ \\
\hline \multirow[t]{5}{*}{ Education } & Not literate@ & & \\
\hline & Literate without any formal schooling & $-0.005[0.011]$ & $0.0[0.01]$ \\
\hline & Formal schooling: till primary & $-0.006 * *[0.003]$ & $-0.009^{* * *}[0.003]$ \\
\hline & Primary to higher secondary & $-0.006^{* *}[0.003]$ & $-0.01^{* * *}[0.003]$ \\
\hline & Graduation to post graduate and above & $-0.012^{* * *}[0.005]$ & $-0.009 * *[0.004]$ \\
\hline \multirow[t]{2}{*}{ Region } & Performer@ & & \\
\hline & Front runner & $-0.0[0.003]$ & $-0.0[0.003]$ \\
\hline \multirow[t]{2}{*}{ Level of care } & Public institution@ & & \\
\hline & Private institution & $-0.01^{* * *}[0.003]$ & $-0.018^{* * *[0.002]}$ \\
\hline \multirow{3}{*}{ Nature of ailment } & Infection@ & & \\
\hline & Other & $-0.022^{* * *}[0.003]$ & $-0.02^{* * *}[0.003]$ \\
\hline & Injuries & $-0.03^{* * *}[0.006]$ & $-0.02 * * *[0.005]$ \\
\hline Household Size & hhs_size & $0.0007[0.0005]$ & $0.0001[0.0004]$ \\
\hline
\end{tabular}

Note: variable@ is reference group, dy/dx: change in dependent variable due to correlates(independent) variables.

Significance level: * $\mathrm{p}<.1 ;{ }^{* *} \mathrm{p}<.05 ;{ }^{* * *} \mathrm{p}<.01$, Standard Error is in the parenthesis.

Source: Authors' estimation.

\section{References}

1 Shih CC, Su YC, Liao CC, Lin JG. Patterns of medical pluralism among adults: results from the 2001 national health interview survey in Taiwan. BMC Health Serv Res. 2010;10(1):1-9.

2 Sujatha V, Abraham L. Medicine, state and society. Econ Polit Wkly. 2009:35-43.

3 World Health Organization (WHO). WHO Traditional Medicine Strategy 2014-2023. World Heal Organ; 2013:1-76. Available from: http://apps.who.int/iris/bitstrea m/10665/92455/1/9789241506090_eng.pdf?ua=1.

4 Azhar G, Amir A, Khalique N, Khan Z. A study of determinants of use of healthcare services in India. Int J Med Publ Health. 2011;1(3):62-66.

5 Chowdhuri PD, Kundu K. Factors determining choice of complementary and alternative medicine in acute and chronic diseases. J Compl Integr Med. 2020;17(3): $1-10$.

6 Pramukh KER, Palkumar PDS. Indigenous knowledge : implications in tribal health and disease. Stud Tribes Tribals. 2006;1(4):1-6.

7 Chauhan RC, Manikandan, Purty AJ, Samuel A, Singh Z. Determinants of health care seeking behavior among rural population of a coastal area in South India. Int $J$ Sci Rep. 2015;1(2):118-122.

8 Dhargupta A, Goswami A, Sen M, Mazumder D. Study on the effect of socio-economic parameters on health status of the Toto, Santal, Sabar and Lodha tribes of West Bengal, India. Stud Tribes Tribals. 2009;7(1):31-38.

9 Jacob I. Health and health seeking behaviour among tribal communities in India: a socio-cultural perspective. J Tribal Intellect Collect India. 2014;2(1):1-16.
10 Latunji OO, Akinyemi OO. Factors influencing health-seeking behaviour among civil servants in Ibadan, Nigeria. Ann Ibadan Postgrad Med. 2018;16(1):52-60.

11 Karanjekar VD, Gujarathi VV, Lokare PO. Sociodemographic factors associated with health seeking behavior of chest symptomatics in urban slums of Aurangabad city , India. Int J Basic Appl Med Sci. 2014;4(1):173-179.

12 Rahman SA, Kielmann T, Mcpake B, Normand C. Healthcare-seeking behaviour among the tribal people of Bangladesh : can the current health system really meet their needs. J Heal Nutr. 2012;30(3):353-365.

13 Babu KS. Socio-economic and health conditions of some major tribes in Andhra Pradesh. From Ed Desk. 2012;1(2).

14 Sarkar AK, Singha S. Factors influencing health of the Santals : a study of selected villages of Birbhum. Int J Community Soc Dev. 2019;1(1):58-74.

15 Sheehan HE. Medical pluralism in India : patient choice or no other options ? Indian J Med Ethics. 2009;6(3):138-141.

16 Sarkar S, Mishra S, Dayal H, Nathan D. Development and deprivation of scheduled tribes. Econ Polit Wkly. 2006;41(46):4824-4827.

17 Anjali D. Relates on tribal education and health : evidence from rural Odisha, India relates on tribal education and health : evidence from rural Odisha, India. Int Res $J$ Soc Sci. 2013;2(11):11-16.

18 Willander E, Bradby H, Torres S, Jonsson P. Conditions for religious pluralism in Swedish hospital chaplaincy : a research note. J Health Care Chaplain. 2019;25(3): 99-109.

19 Falisse J, Masino S, Ngenzebuhoro R. Indigenous medicine and biomedical health care in fragile settings : insights from Burundi. Health Pol Plann. 2018;33(4): 483-493. 
20 Oyebode O, Kandala NB, Chilton PJ, Lilford RJ. Use of traditional medicine in middle-income countries: a WHO-SAGE study. Health Pol Plann. 2016;31(8): 984-991.

21 Singh P, Yadav RJ, Pandey A. Utilization of indigenous systems of medicine \& homoeopathy in India. Indian J Med Res. 2005;122(2):137-142.

22 Srinivasan R, Sugumar VR. Spread of traditional medicines in India: results of national sample survey organization's perception survey on use of AYUSH. J EvidBased Compl Altern Med. 2017;22(2):194-204.

23 Ministry of Statistics and Programme Implementation. Key Indicators of Social Consumption in India Health NSS 71st Round [Internet]. 2015. Available from: htt p://mospi.nic.in/sites/default/files/publication_reports/nss_71st_ki_health_30jun e15.pdf\%0Ahttp://mail.mospi.gov.in/index.php/catalog/161/download/1949.

24 Ministry of Statistics and Programme Implementation. Key Indicators of Social Consumption in India : Health 75th Round. 2019.

25 Ministry of Health and Family Welfare (MoHFW) Government of India. National Health Accounts Estimates for India: 2016-17. Ministry of Health and Family Welfare (MoHFW) Government of India; 2019.

26 Ministry of Ayush. Ayush Annual Report. 2019. 